Canadian Studies in Population 42, no. 3-4 (2015): 1-23.

\title{
Suicide mortality in Canada and Quebec, 1926-2008: An age-period-cohort analysis
}

\author{
Lise Thibodeau ${ }^{1}$
}

\begin{abstract}
This study examines the effects of age, period, and cohort (APC) on male and female suicide risk in Canada from 1926 to 2008. The effects of these factors are also compared between Quebec and the rest of Canada. Both descriptive and APC intrinsic estimator (IE) analyses are used to study variations in suicide rates over this time period. For Canadian males, the risk of suicide is found to increase until age 25 and then level off, whereas among females, the pattern of risk with age forms an inverted " $U$ " shape, with rates peaking in mid-adulthood. Period effects on suicide reached a maximum in the mid-1970s in Canada and approximately a decade later in Quebec; thereafter, in both contexts, suicide rates declined. Cohort effects on suicide are especially pronounced among Quebec males comprising baby-boomer cohorts as well as those belonging to Generation X cohorts. Significant cohort effects are also noted for females, particularly among those born after 1980. These results are interpreted within the framework of Durkheimian theory.
\end{abstract}

Keywords: suicide, age-period-cohort, Intrinsic Estimator (IE), Canada, Quebec.

\section{Résumé}

Cette étude a examiné les effets de l'âge, de période et de cohorte (APC) sur le risque de suicide chez les hommes et les femmes au Canada de 1926 à 2008. Les effets de ces facteurs ont également été comparés entre le Québec et le reste du Canada. Lranalyse descriptive et la modélisation APC Intrinsic Estimator (IE) ont été utilisées pour étudier les variations des taux de suicide au cours de cette période. Pour les hommes canadiens, le risque de suicide a augmenté jusqu'à 25 ans, puis se stabilise, alors que chez les femmes, le profil du risque avec l'âge ressemble à un « $\mathrm{U}$ » inversé avec des taux atteignant un point d'inflexion au milieu de l'âge adulte. Les effets de période sur le suicide ont atteint un maximum au milieu des années 1970 au Canada et environ une décennie plus tard au Québec. Par la suite, les taux de suicide ont diminué dans les deux contextes. Les effets de cohorte sur le suicide ont été particulièrement prononcés chez les hommes québécois comprenant les cohortes des baby-boomeurs ainsi que ceux appartenant à la génération X. Des effets de cohorte importants ont également été observés chez les femmes, en particulier celles qui sont nées après 1980. Ces résultats ont été interprétés selon le cadre théorique de Durkheim.

Mots-clés : suicide, âge-période-cohorte, Intrinsic Estimator (IE), Canada, Québec.

1. Department of Medicine, Research Institute of the McGill University Health Center (RI-MUHC), Royal Victoria Hospital, 687 Pine Avenue West, V-Pavilion (Room V1.09), Montreal QC H3A 1A1. Email: lise.thibodeau@clinepi.mcgill.ca. 


\section{Introduction}

Age-period-cohort (APC) analysis plays an important role in the study of various time-specific phenomena in demography, sociology, epidemiology, and public health. Net (independent) APC dimensions in time are relevant to studies of mortality, especially suicide. The APC approach distinguishes three dimensions of time-related variation, including age effects, in which individuals in a population or subpopulation experience a demographic event as a consequence of their age. The results are given as the distribution of the outcome regardless of cohort. Another dimension of APC analysis constitutes period effects, in which events take place in conjunction with historical circumstances (a transforming immediate social and cultural environment) throughout a studied population (among all age groups). Finally, APC analysis investigates cohort effects ${ }^{2}$ - the behaviours adopted based on cohort membership by individuals born in or around the same year-which reflect lasting differences in the environment, as these individuals lived through the same events (e.g., wars and economic crises) at the same age.

One of the most influential works on suicide mortality is Durkheim's (1951) descriptive sociological study, ${ }^{3}$ which was published at the end of the nineteenth century. Durkheim recognized that statistics allowed observation of consistent patterns in the age and sex of people who died by suicide. First, males committed suicide more often than females. Second, rates increased stably from youth to old age. ${ }^{4}$ Durkheim never clearly explained his findings but suggested that suicide is the result of a long process of experience. Age was never considered as an independent variable in time-related patterns of suicide; instead, it was used to capture the effect of other social variables. The connection between suicide and aging was interpreted as an additional confirmation of the social character of suicide risk. In this framework, the risk of suicide lies outside the individual (not in nature or biology), increasing with time spent in society as collective forces gradually impel people to kill themselves. Both external and collective forces push individuals to commit suicide. The increase in suicide risk with age has remained remarkably constant for more than one and a half centuries, and has thus become known as suicide law. Durkheim's paradigm of integration and regulation strongly influenced contemporary sociology and studies on suicide. ${ }^{5}$

Over the last half-century, however, major changes have occurred in most occidental countries. Importantly, the suicide rate has increased by 60 per cent worldwide, especially among youth. Indeed, at the beginning of the 21 st century, young people were the group at highest risk of suicide in onethird of countries worldwide (WHO 2012). These data challenge Durkheim's suicide law.

Substantial research had been performed on suicide and its demographic pattern of change in Canada (Wasserman 1989; Mao et al. 1990; National Task Force on Suicide in Canada 1994; Stack 2000a, 2000b; Sakinofsky and Webster 2010). Two studies are among the pioneering work on timerelated variation in suicide risk: a study by Reed et al. (1985) that performed a descriptive cohort an-

2. Cohort effect encompasses the shared history of people born in or around the same year, while cohort size or relative cohort size effects represent a proportion of the total population (for example, the proportion of the population aged 15-24 relative to that aged 25-59). Cohort size effect can influence cohort effect but should not be reduced to it.

3. European suicide data from the mid-1850s.

4. "Not only is suicide very rare during childhood but it reaches its height only in old age, and during the interval grows steadily from age to age" Durkheim (1951).

5. Examples of macro studies on suicide are Gibbs and Martin (1958), Johnson (1965), Pope (1976), and Powell (1958). Two examples of micro-level studies are those of Baechler (1975) and Dagenais (2007). Sociological theories on suicide were developed, but new approaches are often similar to the original work of Durkheim and present their own conceptual limitations. 
alysis, and a study by Trovato (1988) that carried this work further by using a classic constrained APC statistical model. Thereafter, other studies using descriptive analysis and APC modeling emerged on this topic. A brief overview of these findings revealed, as Durkheim noted, that men commit suicide more frequently than women, regardless of the time point; only the ratio varies (Reed et al. 1985; Trovato 1988; Mao et al. 1990). Most analyses in that context focused exclusively on males, neglecting changes in the suicide rate among females. Using APC, many Canadian studies in the early 1980s reported that suicide rates grow with age for both sexes, and noted an increase in youth suicide rates from the 1950s through the early 1980s (Reed et al. 1985: 44; Newman and Dyck 1988: 678; Wasserman 1989: 298; National Task Force on Suicide in Canada 1994: 6). A similar pattern of change was observed in Quebec for males under 30 during the 1960s and 1970s (Beaupré and St-Laurent 1998; Thibodeau 2007; Légaré and Hamel 2013: 120), leading analyses to focus exclusively on this population segment (D’Amours 1995, 1996; Caron 2002; Dagenais 2011). There is no conclusive evidence of an effect of period on suicide in Canada, although a strong period effect was reported in descriptive analyses in Quebec, with increased rates among males in all age groups in the 1960s (St-Laurent and Bouchard 2004; Thibodeau 2007; Légaré and Hamel 2013; Légaré et al. 2013). Empirical studies indicated that cohort trends vary, but the effect is primarily observed among males, with more modest (or no) effect for Canadian females, following the general international pattern (Reed et al. 1985: 46; Newman and Dyck 1988: 679; Mao et al. 1990; Légaré and Hamel 2013: 122).

Nonetheless, these analyses are generally dated and limited in scope. While they captured increases in suicide mortality rates over shorter timeframes, these studies did not cover the net (independent) APC effect of sex from vital statistics from 1926 until the beginning of the 21st century, which would provide highly valuable information through the inclusion of additional cohorts. Moreover, national characteristics revealing large societal trends were reported, but previous authors did not discuss the non-uniform distribution of these outcomes across the country. ${ }^{6}$ Suicide rates vary greatly, and these rates historically tend to increase from east to west in Canada (Sakinofsky et al. 1975; Langlois and Morrison 2002: 14; Sakinofsky and Webster 2010: 357); however, an increase in suicide rates in Quebec caused this province to have the highest standardized rate for several years, well above the national average. ${ }^{7}$ In addition, this province is societally unique among Canadian provinces. For example, Quebec is among the most populous provinces and has distinct historic, religious and cultural characteristics dating from its origins as a French colony to its 1763 reincorporation into Canada. Additionally, the challenge in explaining the temporal pattern of change in APC results is to determine whether the process under study results from a combination of age, period, and cohort phenomena, which points to the necessity of statistically estimating and delimiting the age, period, and cohort effects (Yang 2007: 20). Indeed, descriptive analysis presents many advantages and offers an overview of the developments in quantitative temporal age patterns, but is limited because the variables are not independent. APC statistical models allow delimitation of each dimension to estimate the function of each parameter; however, prior studies have not applied the new approaches developed to estimate net APC variations to research on suicide mortality in Canada.

Hence, this study examines the independent APC effects of suicide in Canada by sex from 1926 to 2008 in individuals aged 10 to $90+$ years. This analysis covered a lengthy period in an attempt to uncover trends in Quebec compared to the rest of Canada, ${ }^{8}$ and thus to provide a more complete

6. High suicide rates among aboriginal people in Canada are well documented Canada (see Health Canada 2013), and while research and prevention programs focus on this population segment, this problem is beyond the scope of this study.

7. Available on request to the author.

8. Canadian provinces and territories minus Quebec province. 
and accurate profile of the changes that occurred over 83 years ${ }^{9}$ - encompassing nearly 4 generations of Canadians (33 cohorts were retrieved) and including historical changes in status/gender roles ${ }^{10}$ in society that could affect patterns in suicide rates over time. Specifically, we sought to distinguish whether trends in suicide risk by age have changed over nearly a century in the following ways: (i) whether youth are currently at the highest risk of suicide; (ii) whether particularly sensitive periods can be distinguished; and (iii) whether some cohorts are at greater risk of suicide than others. Correlations with Durkheim's paradigm of integration and regulation provide the theoretical framework in which to interpret our findings. We combined descriptive analysis and a recently developed statistical APC model, the intrinsic estimator (IE), which is used to place findings in socio-historical and cultural context while considering the net effect of each APC dimension.

\section{Data and methods}

The data on the number of suicide deaths in Canada and Quebec cover the period from 1926 to 2008 and consist of publically available datasets from Statistics Canada and the Institut national de santé publique du Québec (INSPQ) for Quebec (1976 to 2008). The age- and sex-specific population estimates for Canada ${ }^{11}$ were derived from census data from Statistics Canada.

Since the Durkheim study, statistics have been the main instrument by which analyses have assessed suicide in the 19th century, but their reliability and validity are often called into question. The prevalence of underestimation in official statistics, also referred to as underreporting, is a commonly debated topic (Overstone 1973; McCarthy and Walsh 1975; Brugha and Walsh 1978; Sainsbury and Jenkins 1982; Walker et al. 2008; De Leo et al. 2010; Rockett et al. 2011; Tollefsen et al. 2012). In Canada, Mao et al. (1990) recognized that suicide mortality is underestimated by official figures, but concluded that the problem is not significant enough to affect the validity of comparisons or hide real differences in suicide rates by province or territory. A subsequent study examining the years 1950-1982 concluded that underestimation was most significant in 1977-1978, with an average estimated underreporting rate of 17.5 per cent for women and 12 per cent for men (Speechley and Stavraky 1991: 38). Underreporting was confirmed in various provinces (Liberakis and Hoenig 1978; Malla and Hoenig 1983; Parai et al. 2006; Edwards et al. 2008); however, it is difficult to obtain even an approximate rate of suicide underestimation in Quebec. Nevertheless, INSPQ concluded that the data on suicide are valid and reliable, that underreporting is not significant in Quebec, and that if corrections were made, the rates would remain essentially the same (St-Laurent and Bouchard 2004: 3). In addition, the International Classification of Diseases (ICD) underwent 8 revisions over the period of our study. According to a compatibility report by the World Health Organization (WHO 1965), only the 7th and 8th ICD revisions affected the comparison of suicide data slightly, with an increase of 3 per cent. Recently, Statistics Canada reported that the change from CIM-9 to CIM-10 had no effect on the number of deaths classified as being due to intentional self-harm (Geran et al. 2005: 10, 33). In this context, the official data were not adjusted for underestimation.

9. The longest time period with publically available data at this time.

10. Stratified analyses are not a constant in the literature, although differences in suicide rates have been highlighted in previous studies (Beaupré and St-Laurent 1998; Keyes and Li 2012; Mao et al. 1990; Thibodeau 2007).

11. Also for Quebec and the rest of Canada. 


\section{Demographic measures}

To avoid random annual rate fluctuations, five-year averages were used for age and period intervals. The data corresponded to individuals aged 10-14 to 90+ years, as suicide before age 10 is rare. ${ }^{12}$ The data were integrated into a cross-tabular format, consisting of Period $\times$ Age $\times$ Sex ${ }^{13}$ The denominator for suicide rate was the total midyear population. After age- and gender-specific rates per 100,000 individuals were calculated, 33 cohorts were identified and per-cohort suicide rates were calculated. Our study used five-year age groupings, so it was necessary to adjust for this range. For commodity cohort suicide rates, allocation followed $C=P-A$ : first year period and first age group. ${ }^{14}$

Furthermore, physical, cognitive personality, and social characteristics of human development can be attributed to different life stages but are not distributed in five-year intervals. Thus, age groups combined by behavioural affinities and human development were used-namely, the stages of life suggested in De Leo and Evans (2003): 15-24 for youth, 25-44 for early adult, 45-64 for mid-adult, and $65+$ for elders. Nevertheless, findings and interpretations related to age are more challenging than age groupings. Age can be understood in demography as a fixed variable in time, while social age varies with perception. Both concepts were taken into account by using Chauvel's (1997) approach to suicide analysis, including context, events, and social factors.

\section{Statistical analysis}

Two approaches were combined for this study. First, we used graphical representations of descriptive analyses of suicide mortality rates by age and sex, and traced a total of 33 cohorts ( $31 \mathrm{IE}$ modeling). Second, an APC statistical model was used to estimate net (independent) effects. The basic APC model of a log linear regression produces the following formula:

$$
\log \left(r_{i j k}\right)=\log \left(\frac{d_{i j k}}{n_{i j k}}\right)=\mu+\alpha_{i}+\beta_{j}+\gamma_{k}+\varepsilon_{i j}
$$

where $r_{i j k}$ represents the expected death rate in an age-period-cohort $(i, j, k) ; d_{i j k}$ denotes the expected number of deaths by suicide; $n_{i j k}$ is the population at risk (exposure); $\mu$ is the intercept or adjusted mean suicide rate; $\alpha_{i}$ is the effect for age groups $i=1, \ldots, \mathrm{a} ; \beta_{j}$ is the effect for time periods $j=1, \ldots, \mathrm{p}$; and $\gamma_{k}$ is the effect for cohorts $k=1, \ldots, \mathrm{c}$; and $\varepsilon_{i j}$ denotes random errors with expectations $\mathrm{E}\left(\varepsilon_{i j}\right)=0$. A unique estimator for Equation 1 in Equation 2 does not exist because the matrix has one less than full column rank (Kupper et al. 1985):

$$
\hat{b}=\left(X^{T} X\right)^{-1} X^{T} Y
$$

is not invertible because APC analysis is impeded by the fundamental problem that the linear function of another dimension (Cohort $=$ Period - Age) presents an identification problem. Specifically, simultaneous estimation attempts for all three linear effects cannot be accomplished in a traditional least-squares regression. This situation is well documented in the APC literature, and attempts to

12. 25 in total during the period of our study in Canada.

13. 16 five-year periods and three years for the last period; 17 five-year age groups (male and female).

14. e.g., cohort 1916 consists of those persons who were 10-14 years of age in 1926-1930; 1916 1913-1918.

This transition from cross-sectional (or period) analysis to cohort analysis is a practical alternative and represents the diagonal of the cross-tabular table, which denotes approximate birth cohorts, as cohort identification is more complex. 
produce sustainable estimations have mainly focused on non-linear effects or imposing arbitrary additional constraints; typically, one (single identification) or more (over-identification) parameters were constrained to be equal. ${ }^{15}$ This technique, presented by Mason et al. (1973)—also referred to as conventional generalized linear models (CGLIM) - implies that statistical model specifications should be grounded on theory; however, parameters estimates are very sensitive to constraints. Rodgers (1982a, 1982b) characterized the debate over the use of APC as follows: "although a constraint of the type described by Mason et al. seems trivial, in fact it is exquisitely precise and has effects that are multiplied so that even a slight inconsistency between the constraint and reality, or small measurement errors, can have very large effects on estimates" (Rodgers 1982a: 785). Other common approaches include models with proxy variables (one or more dummies), but such substitutions may not capture all the components subtracted by the APC dimension.

Our APC analysis was conducted using the IE approach as developed and introduced by Yang and colleagues (Fu 2000; Yang et al. 2004, 2008). Extensive technical algebraic and geometric IE descriptions can be found in the study by Yang et al. $(2004,2008)$. To paraphrase the model developers, IE is a promising alternative modeling approach that yields a unique solution to Equation 1 using a vector-space projection approach. The decomposition of the parameter vector of APC regression design matrix, Equation 1, into two nonparametric component perpendiculars in the orthogonal subspace can be written as follows:

$$
b=\mathrm{B}+s \mathrm{~B}_{0}
$$

where $\mathrm{B}=P_{P r o j} \mathrm{~b}$ is a special parameter vector that is the projection of the parameter vector $\mathrm{b}$ to the non-null space, representing an aggregation of the infinite solutions to the non-invertible matrix; $s$ is a scalar used to multiply sets of vectors in parameter space corresponds to a specific solution among the infinite; $\mathrm{B}_{0}$ is an additive components unique eigenvalue of the matrix design in Equation 2; and $\mathrm{B}$ is the orthogonal complement of $\mathrm{B}_{0}$ (Yang et al. 2008: 1704-05).

The basic idea of the IE $(B)$ is to remove the influence of the design matrix on coefficient estimates. Among its unique proprieties that can be used in APC analysis, $\mathrm{B}_{0}$ is solely a function of the number of age groups and periods and places a constraint on the model that has purely algebraic convenience but is devoid of substantive meaning (Yang et al. 2008: 1707-23). $\mathrm{B}_{0}$ is non-arbitrary and fixed by the design matrix, and the product of $s \mathrm{~B}_{0}$ is an arbitrary value dependant on the arbitrary solution found in the infinite in Equation 2. Third, $B$ in Equation 3, the orthogonal complement to $s \mathrm{~B}_{0}$, represents an IE invariant used to model constraints that is uniquely determined by the Moore-Penrose general inverse (M-P). In fact, although both the CGLIM and IE APC models use generalized inverses, the model associated with the IE estimator, M-P, has some special technical properties that are often cited as an advantage (O'Brien 2011: 434). IE meets Glenn's (2005) criteria for an acceptable all-purpose APC method (Yang et al. 2008: 1732) and does not use a reference category; therefore, less information is lost. This is an asset especially in historical demography studies, in which it is important to track the most parameters possible for each dimension. Another benefit is that IE coefficient estimates are more statistically efficient than CGLIM (Yang et al. 2004: 102). As the IE method is based on the conventional linear model (CGL), it does not allow for the inclusion of covariates (exogenous-independent variables) in the regression. This approach was used by Yang (2008), Keyes and Miech (2013), and Keyes et al. (2014), and it was also applied to a study of suicide in the United States by Phillips (2014). For our study, an algorithm add-on file for calculating the IE

15. i.e., setting the first and second period effects to be equal, by grouping multiple APC pairs. 


\section{Panel A}
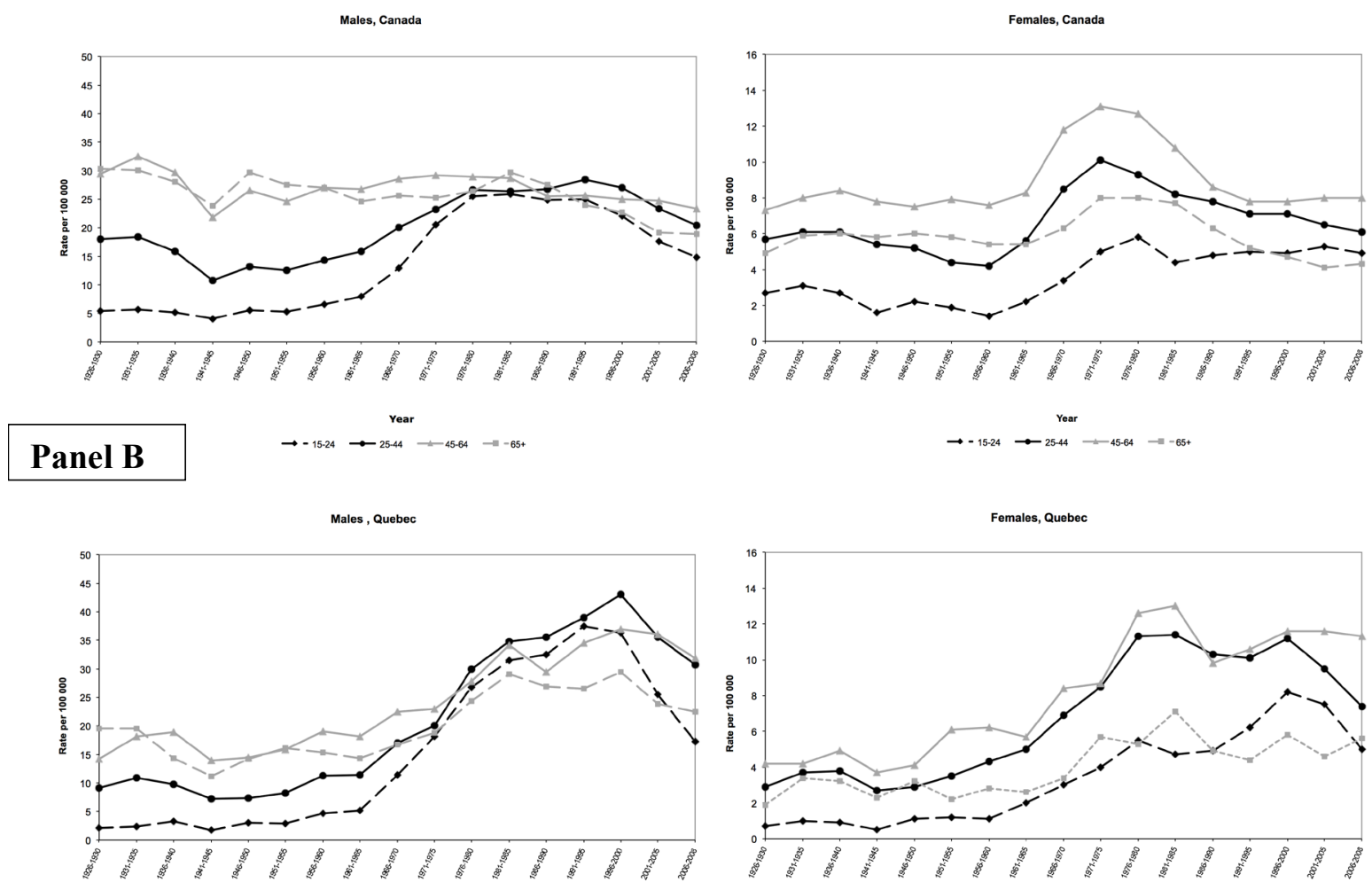

\section{Panel C}

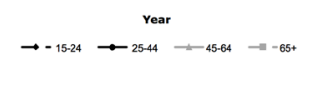

Males, Rest of Canada
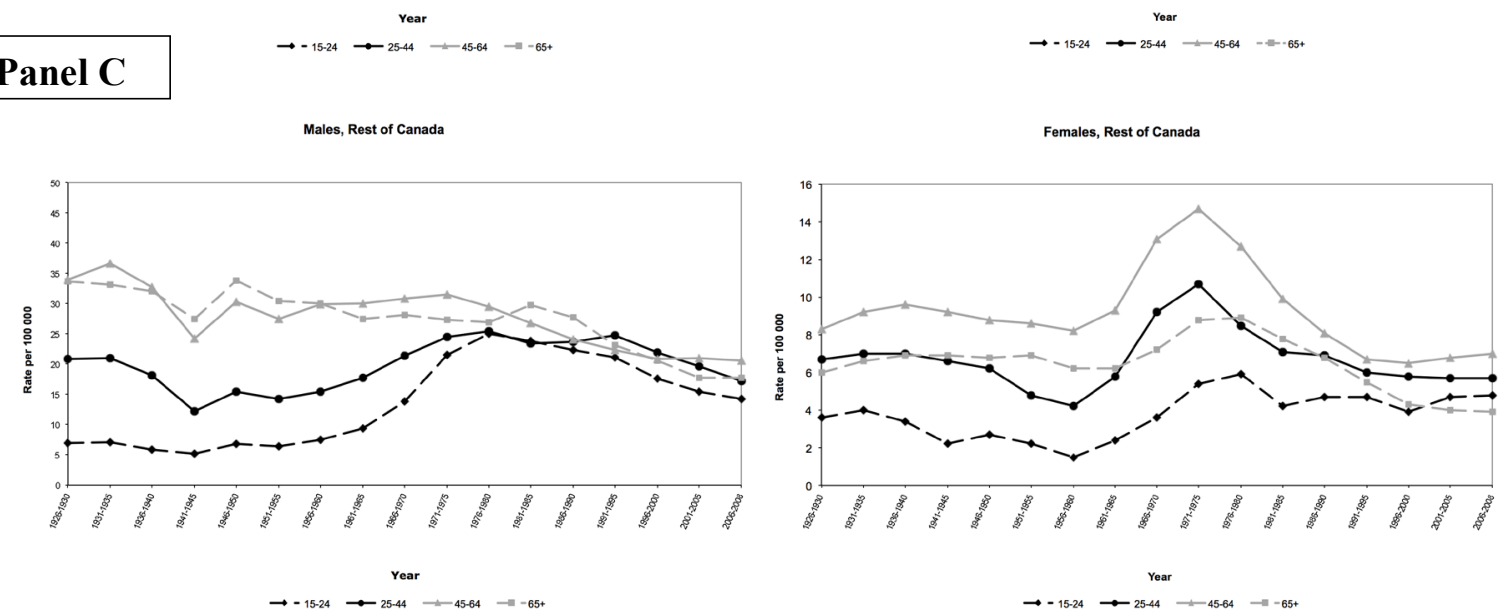

Figure 1. Suicide mortality rates by life stage in males and females: Canada, Quebec, and the rest of Canada, 1926-1930 to 2006-2008.

was obtained from the public domain using the Stata command line ssc install apc (Yang et al. 2008), and results were produced in StataSE version 10.1. The results of the IE analysis are presented in a graph of the log coefficient. 

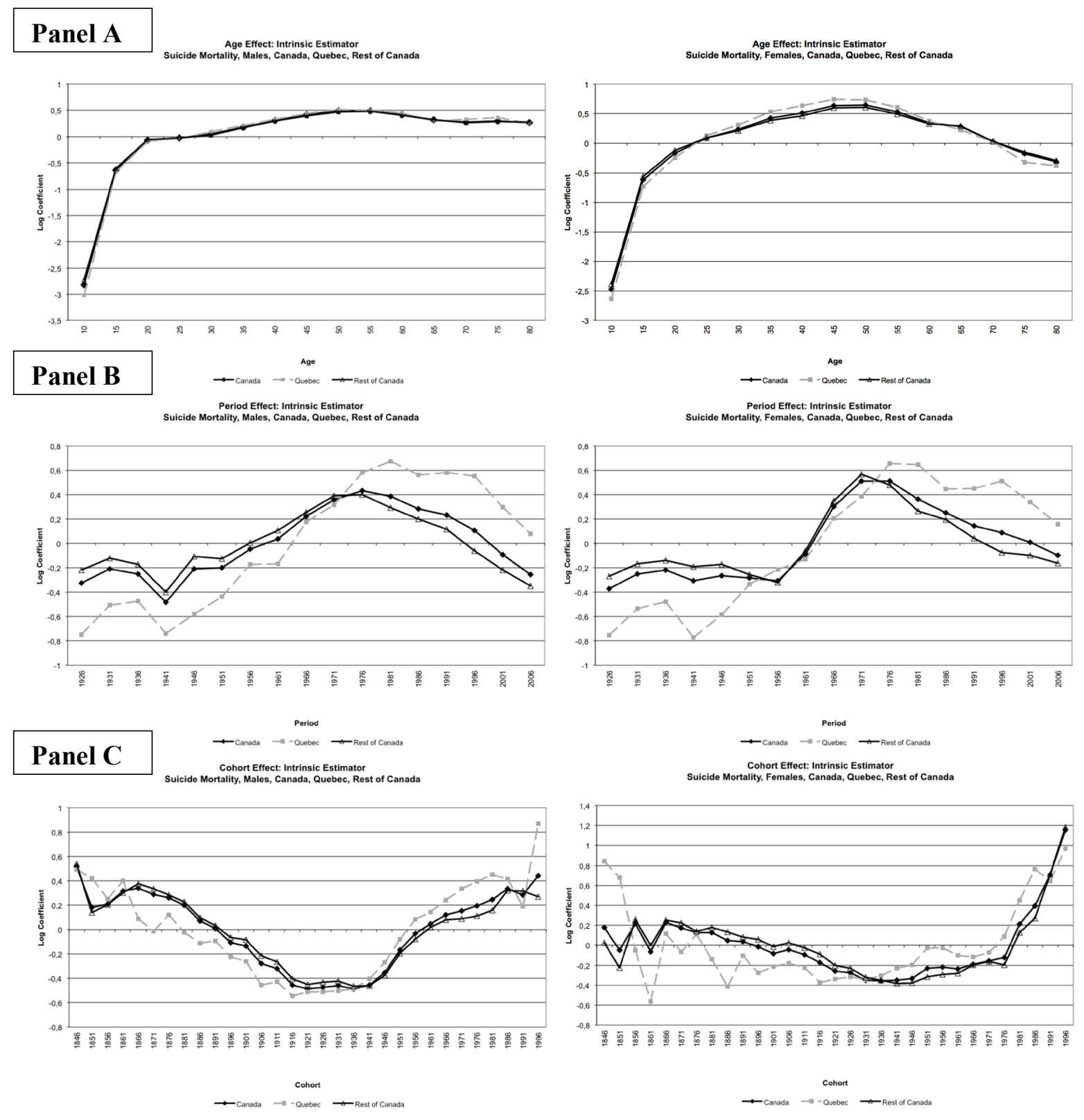

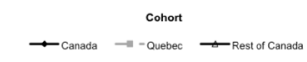

Figure 2. Age-period-cohort effect estimates from the IE for suicide mortality in males and females: Canada, Quebec, and the rest of Canada, 1926-1930 to 2006-2008.

Note: IE-estimated coefficients (Table 1). Canada, Quebec and rest of Canada, available on request to the author.

\section{Results}

\section{Descriptive approach}

Figure 4.1 presents the results of the descriptive analysis of suicide mortality rates aggregated by life stages. From 1926 to 2008 in Canada, suicide rates among male youth (aged 15-24; panel A) increased from 1960 to 1980, and then decreased with subsequent life stages. Over nearly one century, despite the very marked increase in suicide rates among youth, this group was never the most at-risk 
Thibodeau: Suicide mortality in Canada and Quebec, 1926-2008

Table 1. Intrinsic suicide rate estimates for Canada, males and females, 1926-2008.

\begin{tabular}{|c|c|c|c|c|c|}
\hline & \multicolumn{2}{|c|}{ Males } & \multicolumn{2}{|c|}{ Females } \\
\hline & & Coeff. & Std. Err. & Coeff. & Std. Err. \\
\hline \multirow[t]{15}{*}{ Age } & $10-14$ & $-20.8131 * *$ & 0.0902 & $-20.4680 * *$ & 0.0977 \\
\hline & $15-19$ & $-0.6341 * *$ & 0.0379 & $-0.6208 * *$ & 0.0509 \\
\hline & $20-24$ & $-0.0660 * *$ & 0.0311 & $-0.1663 * *$ & 0.0428 \\
\hline & $25-29$ & -0.0277 & 0.0295 & $0.0927 * *$ & 0.0374 \\
\hline & $30-34$ & 0.0483 & 0.0282 & $0.2324 * *$ & 0.0336 \\
\hline & $35-39$ & $0.1797 * *$ & 0.0270 & $0.4227 * *$ & 0.0299 \\
\hline & $40-44$ & $0.3139 * *$ & 0.0265 & $0.5164 * *$ & 0.0283 \\
\hline & $45-49$ & $0.4134 * *$ & 0.0270 & $0.6376 * *$ & 0.0277 \\
\hline & $50-54$ & $0.4913 * *$ & 0.0282 & $0.6456 * *$ & 0.0294 \\
\hline & $55-59$ & $0.4949 * *$ & 0.0305 & $0.5320 * *$ & 0.0336 \\
\hline & $60-64$ & $0.4220 * *$ & 0.0341 & $0.3485 * *$ & 0.0396 \\
\hline & $65-66$ & $0.3229 * *$ & 0.0387 & $0.2794 * *$ & 0.0447 \\
\hline & $70-74$ & $0.2803 * *$ & 0.0438 & 0.0340 & 0.0537 \\
\hline & $75-79$ & $0.3040 * *$ & 0.0503 & $-0.1785 * *$ & 0.0652 \\
\hline & $80-85$ & $0.2700 * *$ & 0.0639 & $-0.3079 * *$ & 0.0806 \\
\hline \multirow[t]{17}{*}{ Period } & 1926 & $-0.3249 * *$ & 0.0533 & $-0.3731 * *$ & 0.0700 \\
\hline & 1931 & $-0.2099 * *$ & 0.0509 & $-0.2502 * *$ & 0.0658 \\
\hline & 1936 & $-0.2486^{* *}$ & 0.0507 & $-0.2167 * *$ & 0.0617 \\
\hline & 1941 & $-0.4839 * *$ & 0.0548 & $-0.3053 * *$ & 0.0600 \\
\hline & 1946 & $-0.2080 * *$ & 0.0479 & $-0.2629 * *$ & 0.0557 \\
\hline & 1951 & $-0.2008 * *$ & 0.0460 & $-0.2854 * *$ & 0.0522 \\
\hline & 1956 & -0.0439 & 0.0415 & $-0.3085 * *$ & 0.0496 \\
\hline & 1961 & 0.0369 & 0.0389 & $-0.0888 * *$ & 0.0428 \\
\hline & 1966 & $0.2239 * *$ & 0.0344 & $0.3029 * *$ & 0.0343 \\
\hline & 1971 & $0.3601 * *$ & 0.0307 & $0.5122 * *$ & 0.0305 \\
\hline & 1976 & $0.4327 * *$ & 0.0286 & $0.5142 * *$ & 0.0307 \\
\hline & 1981 & $0.3871 * *$ & 0.0283 & $0.3632 * *$ & 0.0335 \\
\hline & 1986 & $0.2853 * *$ & 0.0291 & $0.2528 * *$ & 0.0366 \\
\hline & 1991 & $0.2326^{* *}$ & 0.0298 & $0.1460 * *$ & 0.0402 \\
\hline & 1996 & $0.1057 * *$ & 0.0317 & $0.0893 * *$ & 0.0439 \\
\hline & 2001 & $-0.0902 * *$ & 0.0344 & 0.0083 & 0.0480 \\
\hline & 2006 & $-0.2541 * *$ & 0.0423 & -0.0979 & 0.0572 \\
\hline \multirow[t]{13}{*}{ Cohort } & 1846 & 0.5180 & 0.4492 & 0.1806 & 0.7981 \\
\hline & 1851 & 0.1798 & 0.2917 & -0.0492 & 0.4946 \\
\hline & 1856 & 0.2086 & 0.1953 & 0.2208 & 0.2838 \\
\hline & 1861 & $0.3163 * *$ & 0.1439 & -0.0643 & 0.2331 \\
\hline & 1866 & $0.3393 * *$ & 0.1161 & 0.2309 & 0.1688 \\
\hline & 1871 & $0.2878 * *$ & 0.0992 & 0.1732 & 0.1448 \\
\hline & 1876 & $0.2618 * *$ & 0.0851 & 0.1257 & 0.1258 \\
\hline & 1881 & $0.1990 * *$ & 0.0756 & 0.1248 & 0.1101 \\
\hline & 1886 & 0.0715 & 0.0707 & 0.0496 & 0.1005 \\
\hline & 1891 & 0.0080 & 0.0667 & 0.0360 & 0.0915 \\
\hline & 1896 & -0.1057 & 0.0642 & -0.0167 & 0.0846 \\
\hline & 1901 & $-0.1324 * *$ & 0.0591 & -0.0805 & 0.0781 \\
\hline & 1906 & $-0.2774 * *$ & 0.0558 & -0.0428 & 0.0702 \\
\hline WWI and & 1911 & $-0.3187 * *$ & 0.0514 & -0.0942 & 0.0639 \\
\hline \multirow[t]{6}{*}{ WWII } & 1916 & $-0.4554 * *$ & 0.0500 & $-0.1753 * *$ & 0.0590 \\
\hline & 1921 & $-0.4859 * *$ & 0.0470 & $-0.2603 * *$ & 0.0541 \\
\hline & 1926 & $-0.4730 * *$ & 0.0442 & $-0.2761 * *$ & 0.0498 \\
\hline & 1931 & $-0.4615 * *$ & 0.0426 & $-0.3493 * *$ & 0.0475 \\
\hline & 1936 & $-0.4871 * *$ & 0.0426 & $-0.3562 * *$ & 0.0452 \\
\hline & 1941 & $-0.4559 * *$ & 0.0405 & $-0.3497 * *$ & 0.0417 \\
\hline Early baby- & 1946 & $-0.3549 * *$ & 0.0369 & $-0.3317 * *$ & 0.0377 \\
\hline boomers & 1951 & $-0.1670 * *$ & 0.0344 & $-0.2335 * *$ & 0.0349 \\
\hline Late baby- & 1956 & -0.0339 & 0.0334 & $-0.2187 * *$ & 0.0351 \\
\hline \multirow[t]{2}{*}{ boomers } & 1961 & 0.0474 & 0.0344 & $-0.2391 * *$ & 0.0384 \\
\hline & 1966 & $0.1198 * *$ & 0.0381 & $-0.1919 * *$ & 0.0448 \\
\hline Generation & 1971 & $0.1519 * *$ & 0.0444 & $-0.1568 * *$ & 0.0542 \\
\hline$X$ & 1976 & $0.1959 * *$ & 0.0515 & $-0.1251 * *$ & 0.0651 \\
\hline Generation & 1981 & $0.2470 * *$ & 0.0603 & $0.2118 * *$ & 0.0704 \\
\hline \multirow[t]{3}{*}{$\mathrm{Y}$} & 1986 & $0.3343 * *$ & 0.0768 & $0.3959 * *$ & 0.0868 \\
\hline & 1991 & $0.2821 * *$ & 0.1305 & $0.7060 * *$ & 0.1199 \\
\hline & 1996 & 0.4406 & 0.4247 & $10.1561 * *$ & 0.2861 \\
\hline \multicolumn{3}{|c|}{$\overline{\mathrm{BIC}}=598.0373$} & \multicolumn{3}{|l|}{$\mathrm{BIC}=-465.2160$} \\
\hline Intercept (s.e & $=-8.4$ & $271)$ & \multicolumn{3}{|c|}{ Intercept (s.e $)=-9.7703(0.0387)$} \\
\hline Deviance $(\mathrm{d}$. & f. $)=167$ & $(195)$ & Deviance (d.f.) $=$ & $04(195)$ & \\
\hline $\begin{array}{l}\text { Dispersion } \\
* * \text { Statistical }\end{array}$ & $\begin{array}{l}\text { efficien } \\
\text { ly signif }\end{array}$ & $\begin{array}{l}232 \\
\text { at } p<0.0\end{array}$ & Dispersion coeffi & 3.1113 & \\
\hline
\end{tabular}


group. Among elderly men (65+), rates did not substantially change, although a 10-point decrease has occurred since the 1980s. The highest suicide mortality rates were seen at mid-adulthood (45-64) and among the elderly.

Trends among Quebec males (panel B) contrast with those observed in the rest of Canada (panel C), where all suicide rates by life stages remained constant until the end of the 1950s, when a pronounced increase began. Suicide rates among youths and elderly men followed a similar trend. Trends among Quebec females were mostly comparable to those seen in males, though the rates were much lower. Suicide rates among youths and elderly females suicide rates in the rest of Canada generally followed comparable patterns, and neither group was at highest risk during the period of the study. Mid-adult women showed a distinctive increase and decrease in risk by approximately five points from 1960-1980 and were the most at-risk group. ${ }^{16}$

\section{IE analysis}

Figure 4.2 presents the APC-IE estimation results. ${ }^{17}$ Panel A shows the net age effect. The probability of suicide by men in Canada increased considerably from 10-14 to 20-24 years of age and thereafter plateaued, at which time no significant variation was observed across the ages, with a slight peak at approximately 50 years old. The trend among women resembled an inverted " $U$ " shape, in which the risk increased until it reached an inflection point at mid-adulthood, at approximately 45-50 years of age, and then began to decrease from ages 55-59. In Quebec and the rest of Canada, the net age trends were comparable for men and women.

Net period trends in suicide risk mortality (panel B) showed that the risk of suicide by men in Canada fluctuated until the end of the 1930s, increased until 1976-1980, and finally steadily decreased until the end of the 2000s. Suicide risk among Canadian women followed a similar pattern. Quebec and the rest of Canada showed distinct patterns among males and females. The rest of Canada showed a decrease in the net period effect at the beginning of the 1970s, while rates in Quebec continued to increase until 1981-1985 and thereafter oscillated until the end of the century (1996-2000), when they began to decrease. Risk in both sexes in Quebec decreased starting 1941-1945.

Panel C presents the net suicide mortality risk by cohort. Among Canadian males, suicide risk decreased for cohorts born 1846-1916. Then, subsequent cohorts show no net effect until the years 1946-1950 (first baby-boomers). Cohort effects were also seen in subsequent cohorts, with Quebec and the rest of Canada showing similar patterns among males. Canadian females showed no net cohort effect, except in the 1981-1985 cohort, and Quebec and the rest of Canada showed the same trends. $^{18}$

\section{Discussion}

Our analysis of APC trends over 83 years in Canada shows that age, period, and cohort had separate effects on suicide mortality. We interpret our findings in relation to the three research questions and the four characteristics of the patterns seen in suicide rates in Quebec compared to the rest of Canada. Durkheim's classical paradigm of integration and regulation can help explain our results,

16. Data for the graphs by five-year age groups is available on request to the author.

17. To save space, Canadian coefficients are presented in Table 4.1, while tables for Quebec and the rest of Canada are available on request to the author.

18. Cohort descriptive graphs available on request to the author. 
which follow a similar trend as those previously reported in the literature, in which males commit suicide more frequently than females.

\section{Descriptive analysis}

The results of descriptive statistics for Canada show that the greatest changes took place among the youth. Indeed, young males (aged 15-24) experienced an increase of more than 20 points in Canada, ${ }^{19}$ a change not observed in other life stages. This early stage of suicide risk has been documented in studies dating from the late 1980s (Reed et al. 1985; Sakinofsky and Roberts 1987; Dyck et al. 1988; Huchcroft and Tanney 1988; Mao et al. 1990). This pattern of change reflects the largest growth of the youth population during the 1970s in Canada. Individuals are not subject to the same demands at 19 and 55 years of age, while youth have their whole lives ahead of them. So why does suicide rise so sharply among males at this stage of life? Teen suicide can result from a lack of social integration due to the delay or absence of family, professional status, and economic independence. Adolescence is a period of transition between childhood and early adulthood that presents various challenges, including multiple rapid physical, psychological, and social development transformations that are conducive to anomie. Anomie in adolescence arises from the combination of a lack of preparation for entry into adult life and deep dissatisfaction (Dagenais 2007: 151). Although the high rate of suicide mortality in young males (aged 15-24) is commonly misunderstood by the general public, this life stage was never the most at-risk group in Canada over the period of this study. Moreover, there is evidence in the literature of artifacts that affect younger age groups selectively, such as greater acceptance of youth suicide and/or better diagnostics (Holinger 1978: 756). The descriptive statistics seem to indicate the end of this pattern in Canada, with youth suicide rates decreasing for both sexes during the last decade. Similar patterns have been reported in the USA (Phillips 2014: 16).

Also of interest in the context of possible changes in the suicide law is the pattern of change observed in elderly males. In Canada, these individuals were the second most at-risk group for suicide mortality in most of our analyses. This result is consistent with a nearly 25 -year-old descriptive analysis by Mao et al. (1990: 324). Unfortunately, suicide in old age is a much-neglected area of research; in many countries, suicide rates among the elderly are higher than, or as high as, those among youth; this we have found to hold true in Canada for both sexes, and has not been previously reported. ${ }^{20}$ The high suicide rates in elderly males seen for more than seven decades are in keeping with Durkheim's theory of the accumulation of repeated social experiences associated with age. Social cohesion erodes with rising isolation in old age, weakening integration and leading to egoistic suicide. ${ }^{21}$ While rates were high and steady for years, a recent decline in suicide among elderly males and females has occurred since 1980 in Canada. This recent trend was also reported in the USA (Phillips 2014: 16) and in England and Wales (Gunnell et al. 2003), and in the USA has been associated with a range of social and health-related factors (Gunnell et al. 2003: 595). Considering that the number and proportion of seniors in the population will rise substantially in coming decades, more investigation is needed to better understand how the elderly have benefited from suicide prevention in recent decades.

19. 5.5 per 100,000 individuals in 1926-1930 to a maximum of 25.9 in 1981-1985.

20. For example, suicide rates in Canada among elderly males ranged from 30.3 to 22.7 per 100,000 individuals between 1926-1930 and 1996-2000, and this rate only fell below 20 in the last decade. These rates were higher than those for male youth for all periods of our study, except 1991-1995, when there was a 1-point gap.

21. Egoistic suicide refers to suicide resulting from the lack of integration in society. 


\section{IE modeling}

In this analysis, the descriptive statistics and IE estimations show that suicide mortality does not peak among youths or the elderly in Canada, but among mid-adults of both sexes (males 55-59 and 50-54 years old; females aged 45-49 and 50-54). Indeed, our IE modeling reveals a significant ${ }^{22}$ net effect of age on suicide. Among males, suicide mortality rate increases until 25 years of age and then plateaus, with a slight peak at mid-adulthood. Among females, the trend resembles an inverted "U" shape, also with an inflection point at mid-adulthood. Thus, our research extends and strengthens previous descriptive findings by Mao et al. (1990) in Canada, and similar patterns by gender have also been observed in the USA (Riggs et al. 1996; Paulozzi and CDC 2007; Phillips et al. 2010; Phillips 2014). The results obtained for females seem to indicate that net age effects are fairly constant throughout the period of our study. Nonetheless, the "U" shape revealed by IE analysis suggests that variation in suicide rate is especially linked to age among females in Canada.

Our findings do not represent a total breach from Durkheim's suicide law but show the need to investigate trends in suicide during middle age. Interpretative attempts to explain the high suicide rates in middle age in Canada were examined closely and reveal that a substantial part of this net age effect corresponds to the baby-boomer cohorts (1946-1966). This finding is in keeping with findings across the cohorts born from 1951 to 1988 in the USA by Riggs et al. (1996). Therefore, these individuals may have unique risk factors for suicide. Although life expectancy increases over the time period of our study and changes are observed in the distribution of causes of mortality, these factors do not influence suicide rates. A recent study on the impact of change in life expectancy on age-related trends in suicide mortality concluded that there was no relationship among females (Shah 2009: 18). While a significant relationship was seen among males, the author attributed this result to an artifact of the analysis ${ }^{23}$ and concluded that this relationship required further examination (Shah 2009: 19).

The second APC dimension reveals periods influencing suicide mortality in Canada. First, a significant increase in the net effect of period on suicide begins among males from 1946-1950 and among females from 1961-1965, and continues until the end of the 1970s. Significant decreases that begin during 1981-1985 continue until the most recent period studied. Limited and partial examinations of these patterns were conducted in descriptive analyses (Mao et al. 1990: 324; Sakinofsky and Webster 2010: 358), and the results diverge from two previous studies which concluded that period effects are less important than age or have no substantial effect in Canada (Dyck et al. 1988; Wasserman 1989: 307).

How can we make sense of this significant net period effect on suicide? Clearly, the timing matches the modernization era in Canada and its passage from an agricultural to an industrialized society. Durkheim included this transformation "from mechanic to organic society" in his concept of anomie. The lack of social regulation produces anomie, an absence of norms, rapid changes, and the inability of society to meet needs and means (disequilibrium). In the classic Durkheim paradigm, the causes of this increase in suicide are found in the consequences of modernity. The harmful effects of industrialization on societal harmony transform and erode traditional forms of integration and regulation. ${ }^{24} \mathrm{He}$ thus developed the theory that the suicide rate is related to society's ability to main-

22. All coefficients significant at 95 per cent, except for two in Canada and one in Quebec.

23. "Between countries with an increase in suicide rates with increasing age to countries without a change in suicide rates with increasing age" (see Shah 2009).

24. Durkheim defined four types of suicide based on the moral state of society: egoistic (lack of social integration), altruistic (excessive social integration), anomic (inadequate regulation), and fatalistic (overregulation). For the first two types, "suicide varies inversely with the degree of integration of the 
tain control over the individuals who compose it. Durkheim reasoned that "religion, marriage and family, and politics were the important social ties that hold individuals together to society" (Fusé 1997: 83). Modernity is associated with industrialization, urbanization, and parting with traditional ways of life, which all likely contribute to the rise in suicide rates as social cohesion erodes. Indeed, a direct association has been shown between industrialization and suicide in Canada (Labovitz and Brinkerhoff 1977). Moreover, a substantial body of literature has investigated the relation of societal events (family structure, religion, and economic characteristics) to suicide mortality, and the results show, similar to Durkheim, that less socially integrated populations have higher suicide rates (Stack 2000a, 2000b; Phillips 2013). Considerable evidence associated with Durkheim's theory of family integration and its disruption indicates that suicide risk varies directly with the incidence of marital dissolution (Trovato 1986, 1988; Stack 2000b). In Canada, divorced males and females are at higher risk of suicide (Trovato 1992: 126; Leenaars et al. 1993: 919), even after controlling for effects of unemployment and female participation in the labour force (Trovato 1987: 201). Although obvious and strong, the national suicide net period effect among males and females hides the distinctive pattern of change in suicide mortality in Quebec, which is discussed further below.

Our study reveals recent decreases in suicide risk for both sexes in Canada but shows no indication of a major shift in the trend. Nevertheless, the potential impact of certain factors should be highlighted, as they may contribute to the increases and decreases in suicide rates observed during the period studied. Suicide was decriminalized in 1972 (Section 213 was removed from the Criminal Code of Canada), illustrating a change in the cultural view of the act. Other relevant legal changes include modifications to legislation on firearms and amendment in 1984 of the act in Quebec (RSQ) on the causes and circumstances of death research. On the other hand, media resources and different strategies of intervention implemented at the national and provincial levels may have also contributed to the pattern of change. The association of these legislative changes and social changes with suicide mortality in Canada merits additional investigation before making any conclusions about their possible effect on suicide risk.

The third dimension, cohort, displays a strong significant net effect for male baby-boomers (1946-1966) and Generation Xers (1966-1979) in Canada. Thereafter, the momentum oscillates for future cohorts. This net cohort effect for males was distinguished beyond the possible effects of underestimation and lack of reliability of the data (variation in time) in the early period of the study; older male cohorts (1846-1916) showed a decreased suicide rate, and no net effect was seen among the parents of the baby-boomers (1919-1939). Previous analyses agree with our findings (Solomon and Hellon 1980; Reed et al. 1985: 46; Barnes et al. 1986: 208; Newman and Dyck 1988: 679; Mao et al. 1990: 324). Additionally, the progressive increase in the cohort suicide effect among men born after World War II has been observed in other countries, notably the USA, West Germany, Switzerland, UK, Spain, and Japan (Murphy and Wetzel 1980; Hafner and Schmidtke 1985; Granizo et al. 1996; Riggs et al. 1996; Gunnell et al. 2003; Ajdacic-Gross et al. 2006; Odagiri et al. 2011; Keyes and Li 2012); however, our findings and the preponderance of the literature stand in sharp contrast to studies concluding that in Canada cohort is "virtually irrelevant" and "statistically unimportant" in explaining suicide rates (Trovato 1989: 149). Of note, multivariate techniques (least square) were used in these analyses and could represent a source of this disagreement.

social groups of which the individual forms a part" (Durkheim 1951). The other two types are related to the regulative action performed by society, as it is "not only something attracting the sentiments and activities of individuals with unequal force. It is also a power controlling them” (Durkheim 1951). 
People born in the same period experience a succession of favourable and unfavourable collective events that influence demeanour, as they reflect contemporaneous socio-historical contexts beyond individual and societal characteristics. Thus, there is strong reason to believe that behaviour can be influenced by common opportunities and challenges. For groups of men from increasingly suicidal generations, from the first baby-boomers in 1946 to the cohort born in 1976, the relentlessness of social changes until the end of the post-industrialization era represents a "bad spell," reducing protections and increasing suicide risk compared to earlier cohorts. We consider those cohorts to have been affected by the integration factors identified by Durkheim to exist in traditional society. These changes seem to have benefitted females, as their cohorts did not experience such a net effect and appear to be related to the severely increased risk of male suicide. The recent increase in male mortality between cohorts seems to have emerged from different causes, as younger cohorts show inconsistent variations in suicide rates.

Females display no real suicide cohort effect in Canada throughout the period studied, although IE analysis reveals a significant net cohort effect for those born in 1981 and members of Generation Y. This recent suicide net cohort effect for females has not been detected in prior studies in Canada. Province-level analysis reveals the same pattern when comparing Quebec to the rest of Canada, but was qualified in previous work as "weak for those born between 1980 and 1989" (Légaré and Hamel 2013: 122). In the USA, the recently born female cohort shows an increase in the net cohort effect on suicide (Keyes and Li 2012: 422). Although this effect is very recent and involves cohort members in their early 30s or younger, new integration and regulation variables should be examined for those groups. Generation Y is different from the parents of the baby-boomers, "children of the wars," and the baby-boomers. Moreover, cohesion is created differently, depending on factors specific to each generation. Following changes in the 1950s and 1960s, inclusive institutions such as religion and work, as key processes of integration, are no longer running in the same way. Unlike their predecessors, this generation has not been exposed by religion to traditional values; what, then, are their protector factors? Would identity crisis or the fact that the younger Y generation is characterized by independence increase the risk of egoistic suicide? These factors are non-inclusive, as over time and social changes, the meaning of events does not necessarily remain the same. For instance, childbirth out of wedlock was considered "negative" until the beginning of the 21 st century. Moreover, recent female birth cohorts now in their 20s and 30s reconcile motherhood and work differently from the past, and acquire degrees that place them in competition with men for jobs. Therefore, forms of social integration, Durkheimian factors, and new possible unexplained creators of social cohesion should be considered for the younger female cohort. In particular, longitudinal studies should focus on identifying protective and accelerating factors, not only to analyze classical variables that may or may not have retained meaning but also to reflect on their meaning through each generation.

\section{Comparing suicide mortality in Quebec to the rest of Canada}

This study design allowed the comparison of suicide mortality in Quebec to the rest of Canada over the longest period studied to date, and four specific aspects surfaced as a result.

First, suicide rates among male youth (aged 15-24) have increased much more significantly in Quebec than in the rest of Canada, by 35.8 points versus 19.8, respectively. Moreover, this increase is significant compared to any other group in Quebec from 1966-1970 to 1991-1995. The later period 
shows an historic high rate of 37.5 per 100,000. A closer examination reveals very low rates in the earlier periods compared to other life stages before the rates increased, ${ }^{25}$ and this pattern has also been observed in USA (Stockard and O'Brien 2002: 606). These data could have contributed to the misconception that young males constitute the most at-risk life stage in Quebec. Moreover, IE estimations confirm that middle age is the highest-risk age group in Quebec, and a closer examination reveals no difference to the patterns observed in the rest of Canada. Our findings that female suicide in Quebec is most strongly related to age effects agree with a recent study by Legaré et Hamel (2013: 121) that was completed exclusively on Quebec.

Second, IE findings reveal a unique net period effect among females from 1941-1945 in Quebec that has not been found in the rest of Canada. This net effect has also not been previously reported. By one possible interpretation, the decrease in suicide rates might be related to the influence of the Catholic Church in Quebec. Females were encouraged to enter the workplace, for example in military factories or other employment left vacant by males during World War II, which changed their roles during that period (Brandt 1981; Goldin 1991: 741). Although the rest of Canada also saw women greatly contributing to the war effort, in Quebec gender roles were deeply embedded before the war, with the traditional, religion-enforced conceptualization of "exclusive" domestic duties. This "breakout" represented a significant change and shift to a more integrated society. According to Durkheim's theory, wartime encourages stronger cohesion with society, and females additionally benefit from integration through the workplace. However, these new positions were resorbed after the males returned from overseas war duties, and women were directed back to household work, leading to loss of that protection and likely to an increase in their suicide risk.

Although a national net period effect on suicide mortality and the associated societal transformations have been previously discussed, the pattern of change distinct to Quebec province was not. Indeed, the net period effect on increased suicide risk in Quebec extends for both sexes over 10 years (1971-1975 to 1981-1985) compared to the rest of Canada, as marked by slowing and the beginning of a significant decrease. Moreover, the next five-year period (1986-1990) shows a steady and rapid decrease in suicide rates in the rest of Canada, but the risk remains high in Quebec until the end of the century. Quebec only started to follow the trends seen in the rest of Canada in 2001-2005, with a decreased risk of suicide for both sexes.

The origin of the strong and distinctive 25-year net period effect in Quebec compared to the rest of Canada is not definite. The delay in observing the lower suicide risk may be related to the fact that Quebec lagged behind the rest of Canada in modernization (Krull and Trovato 1994: 1124). Duplessis's regime of retour à la terre from the 1930s to 1950s promoted strong traditional religious values, agriculture, and suppression of unions and other change-promoting movements. The Catholic Church and its clergy exercised control over many spheres of Quebec's society, including political and educational institutions. However, in 1960 a new era began. La révolution tranquille (the quiet revolution) overturned Quebec society through rapid modernization, although the long adjustment needed created a substantial period of factors that strongly associate with higher suicide mortality.

Modernization occurred nationwide, but the magnitude and pace of change were remarkable in Quebec. Quebecers committed suicide more frequently than their Canadian counterparts (St-Laurent and Bouchard 2004), and rates in this province reached a historical maximum during this period. Anomie was seen in all the traditional factors described by Durkheim. For example, Durkheim describes

25. Maximum rate per 100,000 individuals (period); youth 1926 to 1965: 5.2 (1961-1965), 1966 to 2000: 37.5 (1991-1995); early adulthood 1926 to 1965: 11.4 (1961-1965), 1965 to 2000: 43.1 (1996-2000); midadulthood 1926 to 1965: 19.1(1956-1960), 1966 to 2000: 36.9 (1996-2000). 
lower suicide rates in rural areas as being related to a fundamental principle of mechanic solidarity (traditional society) characterized by similarity, high influence of religion, and family-based concrete and specific norms. Higher rates in urban areas are related to organic solidarity (modern society), individualism, division of labour, strong secular influence, and an organized occupational base with general and ambiguous norms. Cohesion holds strong via the Catholic Church, but its clergy has experienced a major loss of power with the increased secularization of Quebec. Empirical results show that the lower the importance of religion in society, the higher the suicide rate (Stack 1985; Breault 1986). Alongside the erosion of traditional life, new modern beliefs and ways of life have affected family and political-economic structures and functions.

The decreased importance of the Church and religion have also contributed to changing gender roles, concomitant with a sharp increase in divorces and family instability (Trovato 1988: 41). Our findings point to a widening of the gap between the sexes in suicide risk in this province. A previous study showed that modernization, with the breakdown in traditional forms of integration, is more detrimental to men than to women (Krull and Trovato 1994: 1121). Indeed, male identity has changed rapidly as societal attitudes shifted towards acceptance of married women in the labour force and with the decreased influence of religion. Beyond conjugal anomie, Durkheim remarked on the importance of children, and the 1970s (about the middle of period effect) mark the beginning of declining fertility in all provinces (Grindstaff 1975: 15). An empirical study revealed that having children is more beneficial in reducing suicide risk for males than for females (Krull and Trovato 1994: 1138). These societal transformations might help to explain the observed patterns.

Finally, there is evidence of a stronger significant net cohort effect in males over the last 30-40 years in Quebec, mainly for cohorts of the last baby-boomers and Generation X. Moreover, the effect is less strong for the most recent cohort of Generation $\mathrm{Y}$ in the province, and a plateau with no net cohort effect is seen in the rest of Canada. This result supports findings based only on previous descriptive analyses (Beaupré and St-Laurent 1998; St-Laurent and Bouchard 2004; Thibodeau 2007). However, this finding also contradicts Légaré and Hamel (2013), who conclude that there was "no obvious cohort effect on the variation in suicide rates over the past 60 years" (Légaré and Hamel 2013: 122); however, their analysis did not include periods prior to 1950, and it compares the results to patterns of suicide rates in the USA. Therefore, our comparison appears to be more representative of Quebec. Certainly, the stronger cohort effect seen in males in Quebec suggests the long-lasting impact of societal changes resulting from the révolution tranquille and other shifts presented previously. These changes may have profoundly affected the degree of integration and regulation, producing higher suicide rates for members of those cohorts. Consequently, demographic aspects and societal forms of integration and regulation that may affect those cohorts should be investigated. Example factors include the role of cohort size and environmental influences on Generation-Xers.

\section{Limitations}

Our work shares the limitations of other suicide analyses. First, our study was based on two variables, age and sex; however, suicide is influenced by many other social variables that are closely related. Second, this study was limited by the lack of publicly available statistical information on le suicidé, including the method used, region, marital status, number of children, profession, and religion. Third, parallels and comparisons between international and inter-provincial suicide rates should be undertaken with some caution. Although the countries and provinces reported in this study use the same classification system (ICD), suicide-related behaviours differ based on country life cycle, culture, gender roles, and other factors (e.g., differences in reporting suicide death). The more per- 
missive present climate of Quebec, with its free and open values, could result in a surplus of suicides compared to other Canadian provinces and internationally. Furthermore, observed trends in suicide mortality in the rest of Canada are indicative of general patterns, but additional analysis is needed to address each province and territory, as they may not be homogenous. Moreover, media and other social platforms can play roles in strategy development and in awareness and understanding of suicide mortality. Finally, due to the identification problem, APC models have been criticized and remain a controversial research area. Indeed, these models are evaluated by recent works in the field (Fienberg 2013; Luo 2013a, 2013b; O’Brien 2013; Yang and Land 2013); a recent critical evaluation of APC-IE by Luo (2013a) demonstrates incorrect interpretation of the model, and a number of fallacies are addressed clearly by Yang and Land (2013). APC-IE models differ from Yang's recently developed statistical model, the hierarchical-age-period-cohort (HAPC). The IE approach does not solve the identification problem in APC analysis because there will never be such a solution to the linear relationship $C=P-A$ (Mason et al. 1973; Rodgers 1982a; Yang et al. 2004; O’Brien 2011). Nonetheless, IE has been shown to be useful in expressing relationships among the three time dimensions, has desirable mathematical and statistical properties, and has been validated by studies and simulation tests (Land 2008: 42; Yang et al. 2008: 1707). Although no statistical tools can assist researchers in determining which APC dimension prevails over another, other methodologies also have a place in suicide mortality research. ${ }^{26}$

\section{Conclusion}

In summary, APC analysis reveals net patterns of suicide mortality in Canada for both genders over almost 90 years, providing valuable information to better characterize at-risk groups in a changing society. Meanwhile, four distinct characteristics of the pattern of change in Quebec compared to the rest of Canada are highlighted: a more significant increase in rates among youth; a net period-related decrease among females during World War II; a distinctive 25-year net period effect; and a stronger net cohort effect among the late baby-boomers and Generation-Xers. These insights may be valuable to assess the extent of the public health problem in the province of Quebec. The IE model improves the performance of the APC analysis of suicide in the nation, and the Durkheim paradigm introduces integration and regulation factors to the interpretive discussion of the results. Future studies examining the pattern of change in suicide mortality, how rapidly rates change in certain demographic segments, and the influence of different factors on long-term APC patterns are key to a yet greater understanding of suicide epidemiology. Among other factors, further investigation of patterns of suicide in mid-adulthood is needed. Additionally, our analysis shows strong significant period effects but does not explicitly estimate the effect of economics on suicide rates. Moreover, considering the number and proportion of male baby-boomers who will be entering seniority, which will increase substantially in the coming decades, it will be interesting to follow their journey and monitor how suicide mortality evolves through APC patterns in Canada and its provinces. However, future investigations should be careful in selecting statistical estimator models that allow for covariates, which IE does not. Finally, social forces are complex, and a better understanding of integration and regulation variables, higher-quality data on le suicidé, and further interdisciplinary research on suicide mortality are needed.

26. e.g., non-linear models or models with interaction effects (median polish, non-additive cohort models). 


\section{Acknowledgements}

The author thanks Marianne Kempeneers, $\mathrm{PhD}$, for her continuous support, as well as Vissého Adjiwanou, $\mathrm{PhD}$, and Miss Linda Blouin for their assistance in this study.

\section{References}

Ajdacic-Gross, V., M. Bopp, M. Gostynski, C. Lauber, F. Gutzwiller, and W. Rössler. 2006. Ageperiod-cohort analysis of Swiss suicide data, 1881-2000. European Archives of Psychiatry and Clinical Neuroscience 256:207.

Baechler, J. 1975. Les suicides. Paris: Calmann-Lévy

Barnes, R.A., J. Ennis, and R. Schober. 1986. Cohort analysis of Ontario suicide rates, 1877-1976. The Canadian Journal of Psychiatry 31(3):208-13.

Beaupré, M., and D. St-Laurent. 1998. Deux causes de décès: le cancer et le suicide, in D'une génération à l'autre: évolution des conditions de vie. Sainte-Foy: Bureau de la Statistique du Québec, p. 47-81.

Brandt, G.C. 1981. 'Weaving it together:' Life cycle and the industrial experience of female cotton workers in Quebec, 1910-1950. Labour / Le Travail 7:113-26.

Breault, K.D. 1986. Suicide in America: A test of Durkheim's theory of religious and family integration, 1933-1980. American Journal of Sociology 92(3):628-56.

Brugha, T., and D. Walsh. 1978. Suicide past and present: The temporal constancy of under-reporting. The British Journal of Psychiatry 132(2):177-79.

Caron, J. 2002. Hypothèses macrosociales sur le suicide des hommes au Québec: L'éclairage de l'Abitibi. Santé mentale au Québec 27(2):281-301.

Chauvel, L. 1997. L’uniformisation du taux de suicide masculin selon l'âge: effet de génération ou recomposition du cycle de vie? Revue française de sociologie 38(4):681-734.

D’Amours, Y. 1995. Le point sur la délinquance et le suicide chez les jeunes. Québec: Gouvernement du Québec, Ministere du Conseil executif, Conseil permanent de la jeunesse.

1996. Le suicide chez les jeunes: s.o.s. jeunes en détresse! Quebec: Conseil permanent de la jeunesse, Gouvernement du Québec.

Dagenais, D. 2007. Le suicide comme meurtre d'une identite $\square$. Recherches sociographiques 48(3):139-60. - 2011. Le suicide des jeunes: une pathologie du devenir adulte contemporain. Recherches Sociographiques 52(1):71-104.

De Leo, D., M.J. Dudley, C. Aebersold, J. Mendoza, M. Barnes, J. Harrison, and D.L. Ranson. 2010. Achieving standardised reporting of suicide in Australia: Rationale and program for change. Medical Journal of Australia 192(8):452-56.

De Leo, D., and R. Evans. 2003. International suicide rates: Recent trends and implications for Australia. Canberra: Australian Government Department of Health and Ageing.

Durkheim, É. 1951 [1897]. Suicide: A Study in Sociology. Glencoe, IL: The Free Press.

Dyck, R.J., S.C. Newman, and A.H. Thompson. 1988. Suicide trends in Canada, 1956-1981. Acta Psychiatrica Scandinavica 77:411-19. 
Edwards, N., R. Alaghehbandan, D. MacDonald, K. Sikdar, K. Collins, and S. Avis. 2008. Suicide in Newfoundland and Labrador: A linkage study using medical examiner and vital statistics data. Canadian Journal of Psychiatry 53(4):252-59.

Fienberg, S.E. 2013. Cohort analysis' unholy quest: A discussion. Demography 50(6):1981-84.

Fu, W.J. 2000. Ridge estimator in singular design with application to age-period-cohort analysis of disease rates. Communications in Statistics: Theory and Methods 29(2):263-78.

Fusé, T. 1997. Suicide, Individual and Society. Toronto: Canadian Scholars' Press.

Geran, L., P. Tully, P. Wood, and B. Thomas. 2005. Comparabilité de la CIM-10 et de la CIM-9 pour les statistiques de la mortalité an Canada. Ottawa: Statistique Canada, Division de la statistique de la santé.

Gibbs, J.P., and W.T. Martin. 1958. A theory of status integration and its relationship to suicide. American Sociological Review 23(2):140-47.

—. 1964. Status Integration and Suicide: A Sociological Study. Eugene, OR: University of Oregon Books.

Glenn, N.D. 2005. Cohort Analysis. Thousand Oaks, CA: Sage.

Goldin, C. 1991. The role of World War II in the rise of women's employment. The American Economic Review 81(4):741-56.

Granizo, J.J., E. Guallar, and F. Rodriguez-Artalejo. 1996. Age-period-cohort analysis of suicide mortality rates in Spain, 1959-1991. International Journal of Epidemiology 25(4):814-20.

Grindstaff, C.F. 1975. The Baby bust: Changes in fertility patterns in Canada. Canadian Studies in Population 2:15-22.

Gunnell, D., N. Middleton, E. Whitley, D. Dorling, and S. Frankel. 2003. Why are suicide rates rising in young men but falling in the elderly? A time-series analysis of trends in England and Wales 19501998. Social Science \& Medicine 57(4):595-611.

Hafner, H., and A. Schmidtke. 1985. Do cohort effects influence suicide rates? Archives of General Psychiatry 42(9):926-27.

Health Canada. 2013. National Aboriginal Youth Suicide Prevention Strategy (NAYSPS): Program framework. Ottawa: Health Canada.

Holinger, P.C. 1978. Adolescent suicide: An epidemiological study of recent trends. American Journal of Psychiatry 135(6):754-56.

Huchcroft, S.A., and B.L. Tanney. 1988. Sex-specific suicide trends in Canada, 1971-1985. International Journal of Epidemiology 17(4):839-43.

Johnson, B. 1965. Durkheim's one cause of suicide. American Sociological Review 30(6):875-86.

Keyes, K.M., and G. Li. 2012. Age-period-cohort modeling, in Injury Research Theories, Methods, and Approaches, edited by G. Li and S.P. Baker. New York: Springer, p. 409-26.

Keyes, K.M., and R. Miech. 2013. Age, period, and cohort effects in heavy episodic drinking in the US from 1985 to 2009. Drug and Alcohol Dependence 132(1-2):140-48.

Keyes, K.M., R. Nicholson, J. Kinley, S. Raposo, M.B. Stein, E.M. Goldner, and J. Sareen. 2014. Age, period, and cohort effects in psychological distress in the United States and Canada. American Journal of Epidemiology 179(10):1216-27. 
Krull, C., and F. Trovato. 1994. The quiet revolution and the sex differential in Quebec's suicide rates: 1931-1986. Social Forces 72(4):1121-47.

Kupper, L.L., J.M. Janis, A. Karmous, and B.G. Greenberg. 1985. Statistical age-period-cohort analysis: A review and critique. Journal of Chronic Diseases 38(10):811-30.

Labovitz, S., and M.B. Brinkerhoff. 1977. Structural changes and suicide in Canada. International Journal of Comparative Sociology 18:254-67.

Land, K.C. 2008. Disentangling age-period-cohort effects: New models, methods, and empirical applications. PRI Summer Methodology Workshop Presentation, Pennsylvania State University (June 16).

Langlois, S., and P. Morrison. 2002. Suicide et tentatives de suicide. Rapports sur la santé 13(2):9-25.

Leenaars, A.A., B. Yang, and D. Lester. 1993. The effect of domestic and economic stress on suicide rates in Canada and the United States. Journal of Clinical Psychology 49(6):918-21.

Légaré, G., and D. Hamel. 2013. An age-period-cohort approach to analyzing trends in suicide in Quebec between 1950 and 2009. Canadian Journal of Public Health 104(2):118-23.

Légaré, G., M. Gagné, and D. St-Laurent. 2013. La mortalité par suicide au Québec: 1981 à 2010. Direction de l'analyse et de l'évaluation des systèmes de soins et services. Québec: Institut national de santé publique du Québec.

Liberakis, E.A., and J. Hoenig. 1978. Recording of suicide in Newfoundland. Psychiatric Journal of the University of Ottawa 3(4):254-59.

Luo, L. 2013a. Assessing validity and application scope of the intrinsic estimator approach to the ageperiod-cohort problem. Demography 50(6):1945-67.

- 2013b. Paradigm shift in age-period-cohort analysis: A response to Yang and Land, O'Brien, Held and Riebler, and Fienberg. Demography 50(6):1985-88.

Malla, A., and J. Hoenig. 1983. Differences in suicide rates: an examination of under-reporting. Canadian Journal of Psychiatry 28(4):291-93.

Mao, Y., P. Hasselback, J.W. Davies, R. Nichol, and D.T. Wigle. 1990. Suicide in Canada: An epidemiological assessment. Canadian Journal of Public Health 81(4):324-28.

Mason, K.O., W.M. Mason, H.H. Winsborough, and W.K. Poole. 1973. Some methodological issues in cohort analysis of archival data. American Sociological Review 38(2):242-58.

McCarthy, P.D., and D. Walsh. 1975. Suicide in Dublin: I. The under-reporting of suicide and the consequences for national statistics. British Journal of Psychiatry 126:301-08.

Murphy, G.E., and R.D. Wetzel. 1980. Suicide risk by birth cohort in the United States, 1949 to 1974. Archives of General Psychiatry 37(5):519-23.

National Task Force on Suicide in Canada. 1994. Suicide in Canada: Report of the National Task Force on Suicide in Canada 1987. Ottawa: Department of National Health and Welfare.

Newman, S.C., and R.J. Dyck. 1988. On the age-period-cohort analysis of suicide rates. Psychological Medicine 18(3):677-81.

O’Brien, R.M. 2011. Constrained estimators and age-period-cohort models. Sociological Methods \& Research 40(3):419-52. 
2013. Comment on Liying Luo's article 'Assessing validity and application scope of the intrinsic estimator approach to the age-period-cohort problem.' Demography 50(6):1973-75.

Odagiri, Y., H. Uchida, and M. Nakano. 2011. Gender differences in age, period, and birth-cohort effect on suicide mortality rate in Japan 1985-2006. Journal of Public Health 23(4):581-87.

Overstone, I.M.K. 1973. A psychiatric approach to the diagnosis of suicide and its effect upon the Edinburgh statistics. British Journal of Psychiatry 123(572):15-21.

Parai, J.L., N. Kreiger, G. Tomlinson, and E.M. Adlaf. 2006. The validity of the certification of manner of death by Ontario coroners. Annals of Epidemiology 16(11):805-11.

Paulozzi, L.J., and CDC (Centers for Disease Control and Prevention). 2007. Increases in age-groupspecific injury mortality: United States, 1999-2004. Morbidity and Mortality Weekly Report 56(49):128184.

Phillips, J.A. 2013. Factors associated with temporal and spatial patterns in suicide rates across U.S. States, 1976-2000. Demography 50(2):591-614.

- 2014. A changing epidemiology of suicide? The influence of baby boomers on suicide rates in the United States. Social Science \& Medicine 114:151-60.

Phillips, J.A., A.V. Robin, C.N. Nugent, and E.L. Idler. 2010. Understanding recent changes in suicide rates among the middle-aged: Period or cohort effects? Public Health Reports (1974-) 125(5):680-88.

Pope, W. 1976. Durkheim's Suicide: A Classic Analyzed. Chicago: University of Chicago Press.

Powell, E.H. 1958. Occupation, status, and suicide: Toward a redefinition of anomie. American Sociological Review 23(2):131-39.

Reed, J., J. Camus, and J. Last. 1985. Suicide in Canada: Birth-cohort analysis. Canadian Journal of Public Health 76:43-47.

Riggs, J.E., R.L. McGraw, and R.W. Keefover. 1996. Suicide in the United States, 1951-1988: Constant age-period-cohort rates in 40- to 44-year-old men. Comparative Psychiatry 37(3):222-25.

Rockett, I.R.H., N.D. Kapusta, and R. Bhandari. 2011. Suicide misclassification in an international context: Revisitation and update. Suicidology Online 2:48-61.

Rodgers, W.L. 1982a. Estimable functions of age, period, and cohort effects. American Sociological Review 47(6):774-87.

- 1982b. Reply to comment by Smith, Mason, and Fienberg. American Sociological Review 47(6):79396.

Sainsbury, P., and J.S. Jenkins. 1982. The accuracy of officially reported suicide statistics for purposes of epidemiological research. Journal of Epidemiology and Community Health 36(1):43-48.

Sakinofsky, I., and R. Roberts. 1987. The ecology of suicide in provinces of Canada, 1969-71 to 1979-81, in The Epidemiology of Psychiatric Disorders, edited by B. Cooper. Baltimore: Johns Hopkins, p. $27-42$.

Sakinofsky, I., and G. Webster. 2010. The epidemiology of suicide in Canada, in Mental Health in Canada: The Epidemiologic Perspective, edited by J. Cairney and D.L. Streiner: University of Toronto Press, p. 357-89. 
Sakinofsky, I., R. Roberts, and A.T. Van Houten. 1975. The End of the Journey: A Study of Suicide Across Canada and the Social Correlates of Suicide. 8th Annual Meeting International Association of Suicide Prevention (IASP). Jerusalem.

Shah, A. 2009. Are age-related trends in suicide rates associated with life expectancy and socioeconomic factors? International Journal of Psychiatry in Clinical Practice 13(1):16-20.

Solomon, M.I., and C.P. Hellon. 1980. Suicide and age in Alberta, Canada, 1951 to 1977: A cohort analysis. Archives of General Psychiatry 37(5):511-13.

Speechley, M., and K.M. Stavraky. 1991. The adequacy of suicide statistics for use in epidemiology and public health. Canadian Journal of Public Health 82(1):38-42.

St-Laurent, D., and C. Bouchard. 2004. L'Épidémiologie du suicide au Québec: que savons-nous de la situation récente? Direction de la planification, de la recherche et de l'innovation, Unité connaissancesurveillance. Montréal: Institut national de santé publique.

Stack, S. 1985. The effect of domestic/religious individualism on suicide, 1954-1978. Journal of Marriage and Family 47(2):431-47.

. 2000a. Suicide: A 15-year review of the sociological literature. Part I: Cultural and economic factors. Suicide and Life Threatening Behavior 30(2):145-62.

2000b. Suicide: A 15-year review of the sociological literature. Part II: Modernization and social integration perspectives. Suicide and Life Threatening Behavior 30(2):163-76.

Stockard, J., and R.M. O'Brien. 2002. Cohort variations and changes in age-specific suicide rates over time: Explaining variations in youth suicide. Social Forces 81(2):605-42.

Thibodeau, L. 2007. Lecture sociodémographique de l'évolution de la mortalité par suicide au Québec (1926-2004): la question de l'âge et des générations. Mémoire de maîtrise (M.Sc.) en Sociologie, Département de sociologie, Université de Montréal.

Tollefsen, I.M., E. Hem, and O. Ekeberg. 2012. The reliability of suicide statistics: A systematic review. BMC Psychiatry 12(1):9.

Trovato, F. 1986. The relationship between marital dissolution and suicide: The Canadian case. Journal of Marriage and Family 48(2):341-48.

- 1987. A longitudinal analysis of divorce and suicide in Canada. Journal of Marriage and Family 49(1):193-203.

- 1988. Suicide in Canada: A further look at the effects of age, period and cohort. Canadian Journal of Public Health 79:37-44.

1989. Age, period and cohort effects on suicide: A reply. Canadian Journal of Public Health 80(2):149. 43.

Walker, S., L. Chen, and R. Madden. 2008. Deaths due to suicide: The effects of certification and coding practices in Australia. Australian New Zealand Journal of Public Health 32(2):126-30.

Wasserman, I.M. 1989. Age, period and cohort effects in suicide behavior in the United States and Canada in the 20th century. Journal of Aging Studies 3(4):295-311. 
WHO (World Health Organization / Organisation mondiale de la santé). 1965. Comparability of Mortality Statistics for the Sixth and Seventh Revisions: United States, 1958. Washington: U.S. Public Health Service, National Center for Health Statistics.

- 2012. Suicide prevention (SUPRE): Live your life. Public Health Action for the Prevention of Suicide. Geneva: WHO Department of Mental Health and Substance Dependences NonCommunicable Diseases and Mental Health. http://www.who.int/mental_health/management/en/ SUPRE_flyer1.pdf

Yang, Y. 2007. Age-period-cohort distinctions, in Encyclopedia of Health \& Aging, edited by K.S. Markides. Thousand Oaks, CA: Sage, p. 20-23.

- 2008. Trends in U.S. adult chronic disease mortality, 1960-1999: Age, period, and cohort variations. Demography 45(2):387-416.

Yang, Y.C., and K.C. Land. 2013. Misunderstandings, mischaracterizations, and the problematic choice of a specific instance in which the IE should never be applied. Demography 50(6):1969-71.

Yang, Y., W.J. Fu, and K.C. Land. 2004. A methodological comparison of age-period-cohort models: The intrinsic estimator and conventional generalized linear models. Sociological Methodology 34(1):75110.

Yang, Y., S. Schulhofer-Wohl, W.J. Fu, and K.C. Land. 2008. The intrinsic estimator for age-periodcohort analysis: What it is and how to use it. American Journal of Sociology 113(6):1697-1736. 